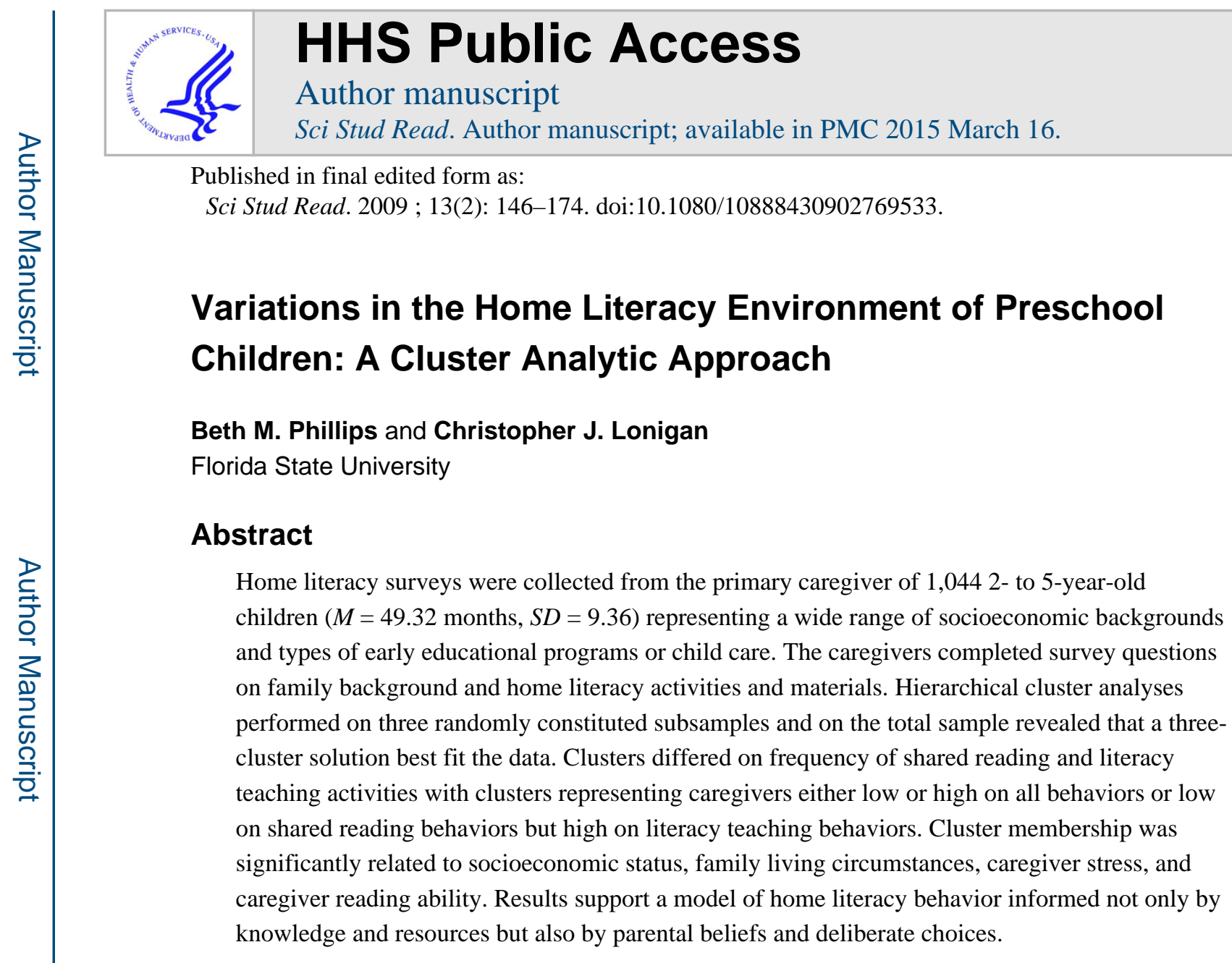

The cumulative research of the past several decades has led to an increasingly sophisticated understanding of the early childhood underpinnings of reading ability (e.g., Lonigan, 2006; Storch \& Whitehurst, 2002; Wagner, Torgesen, \& Rashotte, 1994; Whitehurst \& Lonigan, 1998). These collective findings lend support to a concept of emergent literacy as a skill set and knowledge base that begins developing in infancy and that is enriched across the early childhood period by exposure to language, printed materials, and opportunities for exploratory and instructional encounters with literacy materials. Specifically, research indicates that oral language, phonological awareness, and print knowledge are the core components of a strong emergent literacy foundation (Whitehurst \& Lonigan, 1998).

A related body of research has explored the contributions of home factors to the development of these key emergent literacy skills. Most research on the home literacy environment (HLE) has focused on shared reading, which has, across studies and despite some variability in magnitude, consistently been related to emergent literacy outcomes (e.g., Bus, van IJzendoorn, \& Pellegrini, 1995; Dunning, Mason, \& Stewart, 1994; Lonigan, 1994; Payne, Whitehurst, \& Angell, 1994; Scarborough \& Dobrich, 1994). Shared reading encounters in the home are associated with growth in children's vocabulary and other oral language skills in young children (e.g., Leseman \& de Jong, 1998; Sénéchal \& Cornell, 1993; Sénéchal, LeFevre, Hudson, \& Lawson, 1996). Data from home- and school-based

Correspondence should be sent to Beth M. Phillips, Department of Education Psychology and Learning Systems and the Florida Center for Reading Research, Florida State University, 227 North Bronough Street, Suite 7250, Tallahassee FL 32301. bphillips@fcrr.org. 
intervention studies also support these correlational findings (e.g., Lonigan \& Whitehurst, 1998; Whitehurst et al., 1994). When adults instinctually or with training emphasize the child's participatory role and facilitate enriched expressive vocabulary practice, positive effects are found on children's oral language skills.

Home literacy studies focused exclusively on shared reading interactions have found that its primary impact is on oral language rather than phonological awareness or print knowledge (e.g., Lonigan, Dyer, \& Anthony, 1996; Raz \& Bryant, 1990). However, studies using a richer, more diverse HLE construct support relations with both language and vocabulary skills and with the code-related skills (e.g., Burgess, 2002; Christian, Morrison, \& Bryant, 1998; Evans, Shaw, \& Bell, 2000; Levy, Gong, Hessels, Evans, \& Jared, 2006; Sénéchal \& LeFevre, 2002; Sénéchal, LeFevre, Thomas, \& Daley, 1998). These researchers suggest that the HLE is better defined as encompassing variables such as literacy artifacts, functional uses of literacy, verbal references to literacy, library use, parental encouragement and value of reading, parental teaching of skills, child interest, parental modeling of literacy behaviors, parental education, and parental attitudes toward education. Further, some of these studies indicate a degree of modularity in the influence of home activities on emergent literacy skills. For example, the work by Sénéchal and colleagues (Sénéchal \& LeFevre, 2002; Sénéchal et al., 1998) and Evans and colleagues (Evans et al., 2000; Levy et al., 2006) indicated that specific parental instruction, but not shared reading, predicted phonological awareness, print knowledge, or both.

One influential perspective on emergent literacy that may help to explain some of these findings is the model presented by Whitehurst and Lonigan (1998) in which they conceptualized the skills needed for successful reading as falling into either outside-in or inside-out domains. The outside-in domain includes the language, vocabulary, content, and narrative understanding skills that allow for listening, and ultimately reading comprehension abilities for individual words and connected texts. In contrast, the inside-out domain focuses on word-specific decoding and foundational skills such as alphabet knowledge, phonological awareness, and phonemic decoding capacities that allow the individual words to be correctly decoded and mapped to the outside-in vocabulary and context knowledge. Numerous recent studies support this general framework, and the central tenet indicating that oral language, vocabulary, print knowledge, and phonological awareness are each necessary but individually insufficient skill sets predictive of and causally related to reading ability (e.g., Lonigan, Schatschneider, Westberg, \& the National Early Literacy Panel, in press; Sénéchal \& LeFevre, 2002; Shatil \& Share, 2003; Storch \& Whitehurst, 2002).

There appear to be consistent differences in the emergent literacy skills of children from different socioeconomic status (SES) and sociocultural backgrounds. Research with children from lower SES backgrounds and with some minority populations indicates that there is a clear and substantial gap in the emergent literacy skills for children from at-risk backgrounds relative to their more affluent peers and children from homes with more educated parents (e.g., Bowey, 1995; Chaney, 1994; Hecht, Burgess, Torgesen, Wagner, \& Rashotte, 2000; Lonigan, Burgess, Anthony, \& Barker, 1998; Raz \& Bryant, 1990). These findings of skill differences emerging as young as 2 and 3 years of age are a concern, given the growing evidence that children who begin behind their peers in early reading 
development most often stay behind in the absence of, or despite, intensive remedial or intervention efforts (e.g., Juel, 1988; Lovett, Bordon, DeLuca, Lacerenza, Benson, \& Brackstone, 1994; Torgesen, 2005; Torgesen et al., 2001).

Research supports the suggestion that variability in the home environment is a key explanation for some of the SES and cultural performance differences. There are consistent findings that social class differences exist in the frequency with which parents engage in shared reading activities with their children (Burgess, Hecht, \& Lonigan, 2002; Feitelson \& Goldstein, 1986; Leseman \& de Jong, 1998; McCormick \& Mason, 1986). For example, Baker, Fernandez-Fein, Scher, and Williams (1998) found that whereas more than $90 \%$ of the families of middle-income background engaged in daily book reading, only $52 \%$ of the families of lower income background did so. Karass, VanDeventer, and Braungart-Ricker (2003) found that even within an exclusively middle-income sample in which all parents had a least a high school degree, income was associated with onset of maternal shared reading with infants, as was parenting stress. The research on the home environment that has looked beyond shared reading also shows wide variability across families (e.g., Burgess et al., 2002; Frijters, Barron, \& Brunello, 2000; Leseman \& de Jong, 1998; Lonigan, 1994; Payne et al., 1994; Sénéchal \& Lefevre, 2002; Storch \& Whitehurst, 2001). Many of the lower SES families in Purcell-Gates's (1996) study "lived busy and satisfying lives with very little mediation by print" (p. 425) and thus spent little if any time reading with or exposing their children to print.

Although it is unclear whether ethnicity can be dissociated fully from SES, the Federal Interagency Forum on Child and Family Statistics (2003) reported that whereas 64\% of Caucasian families read to their children daily, only $48 \%$ of African American and $42 \%$ of Hispanic parents said they did so; this report also revealed that frequency of shared reading was associated positively with maternal education and negatively with poverty. BrooksGunn and Markman (2005) and Yarosz and Barnett (2001) found similar ethnicity-linked differences in home reading. Research reveals that SES and cultural groups cannot be treated as homogeneous, as there is often substantial variation within group on behavior, values, and child outcomes (Bradley \& Corwyn, 2002; Christian et al., 1998; Fish \& Pinkerman, 2003; Payne et al., 1994; Weizman \& Snow, 2001). Despite restricted finances and limited education, many parents with lower SES do provide an enriched, supportive HLE (Christian et al., 1998; Drummond \& Stipek, 2004; Payne et al., 1994; Purcell-Gates, 1996). Two recent studies of Head Start attendees showed clear evidence of variability in home literacy environments (Farver, Xu, Eppe, \& Lonigan, 2006; Foster, Lambert, AbbottShim, McCarty, \& Franze, 2005).

Work by Sénéchal and others also suggests that there are distinctions within and across SES and cultural lines between parents' engagement in activities contributing to outside-in and inside-out skill areas (e.g., Baker et al., 1998; Baker, Scher, \& Mackler, 1997; Evans et al., 2000; Sénéchal \& LeFevre, 2002; Sénéchal et al., 1998; Serpell, Sonnenschein, Baker, \& Ganapathy, 2002). That is, low correlations have been found between parental reports of shared reading and book exposure activities and reports of letter- and sound-focused activities. Research on parental behaviors within the context of book reading also indicates that there are wide variations in the frequency and type of readers' extratextual comments, 
degree of abstraction in these comments, and the amount of focus on print features (Danis, Bernard, \& Leproux, 2000; Goodsitt, Raitan, \& Perlmutter, 1988; Hammett, van Kleeck, \& Huberty, 2003; Justice \& Ezell, 2002).

Baker and colleagues conceptualize the differences in parental focus as evocative of perspectives on early literacy acquisition that have a "literacy as entertainment" or "literacy as skill" based motivation. These and other studies do find belief- and practice-relations consistent with this theory and suggest that parents from lower income backgrounds more readily endorse a skills-focused perspective, and didactic teaching methods, as appropriate and relevant for young children (e.g., Baker et al., 1998; Baker et al., 1997; DeBaryshe, 1995; Stipek, Feiler, Daniels, \& Milburn, 1995; Stipek, Milburn, Clements, \& Daniels, 1992). These findings imply that parents who view literacy as an aspect of cultural competency, enjoyment, and general enrichment, rather than solely as a functional and academic skill set, are more likely to preferentially or exclusively engage in book-related activities that will impact children's outside-in skills rather than activities geared toward inside-out skills. One source for parents' beliefs and behavioral preferences may be that middle-income parents may have been exposed to and internalized the more extreme versions of constructivist philosophy on emergent literacy that suggest children's abilities should be developed only within nondidactic interactions rather than with parent- or teacherdirected interactions (e.g., Bredekamp \& Copple, 1997; Elkind, 1987).

Several shortcomings of the SES and parent-behavior research restrict the conclusions that may be drawn with confidence. First, the studies just noted are exclusively correlational in design. Second, these studies are limited to a variable-centered perspective, leaving open the question of how these variables might form patterns within families and types of families. Other limitations include the frequent lack of control for financial capital and access to resources (e.g., with which to purchase books for the home) and the fact that some of the parental-report measures were designed with entertainment and skill goals as mutually exclusive choices or as opposite ends of a single continuum (e.g., DeBaryshe \& Binder, 1994). It is likely that parental beliefs and behaviors about appropriate and relevant literacy activities are more complexly related than the dichotomized perspectives would seem to suggest. For example, in a study with Caucasian, Latino, and African American families with children 4 to 6 years of age, all parents considered preacademic skills (e.g., knowing letters) to be equally important as socioemotional behaviors (e.g., paying attention) for kindergarten success (Diamond, Reagan, \& Bandyk, 2000). Other survey studies indicate that parents of preschool children actually are more likely than the teachers to endorse early academic skills like knowing letters and numbers as important for school readiness (Knudsen-Lindauer \& Harris, 1989; Piotrkowski, Botsko, \& Matthews, 2000).

The possibility also exists that in addition to parental beliefs about literacy driving their behaviors, parental assessments of child skill drives their behaviors (Drummond \& Stipek, 2004; Potter, 1995). In other words, parents who recognize that their children are lacking in a rudimentary understanding of letter names and sound manipulation may be more likely to engage in skill-focused activities with their children. Conversely, parents whose children show more advanced skills may not feel compelled to teach early code-related content and may develop belief systems and behavioral preferences that exclude a focus on inside-out 
behaviors. Because low skill levels cluster within children from lower SES and minority groups, this could be another factor leading to the cultural divide seen in some studies of parental perspective and behaviors. In all likelihood, there is a reciprocal influence leading both to distinctions in parental preferences and in child skill development. Support for the possibility of bidirectional influences comes in part from research on children's early language development that shows parents and children both being influenced by the others' current and prior language use and style (Baumwell, Tamis-LeMonda, \& Bornstein, 1997; Olson, Bates, \& Bayles, 1984).

\section{PERSON-CENTERED STUDIES}

The primary motivation for this study was to address the gap in our understanding given that most prior studies on the home literacy and language environments have had variable- rather than person-focused perspectives. The most notable exceptions are a recent study by Hammett et al. (2003) and research by Haden, Reese, and Fivush (1996), both of which focused exclusively on cluster analyses of behaviors related to shared book reading. The most comparable previous study used cluster analyses to profile the parenting practices of parents of preschool-age children (Brenner \& Fox, 1999). Their findings indicated stable clusters of parenting behaviors, including home shared reading behaviors, with significant external correlations to sociodemographic variables such as maternal education, family income, and the number of children in the home.

\section{THIS STUDY}

This study takes advantage of a very large, socioeconomically and ethnically diverse sample of parents to explore questions of parental early language- and literacy-focused behaviors from a cluster-analytic perspective. This article extends the literature by including the largest sample to date in which parents of young children were asked questions about both shared reading and code-related activities, in that it asks not only about alphabet and print focused activities but also about rhyming games, an aspect of phonological awareness. The application of a person-focused methodology allows one to explore the intraindividual profiles and dynamic relations among the behavioral options available to parents in creating their own home literacy environment (DiStefano \& Kamphaus, 2006) and to better understand how family context, including SES, may shape these choices. Specifically, the goal of our study was to extend the variable-centered findings of low correlations between outside-in and inside-out directed home literacy practices by profiling behaviors within families. We predicted that rather than finding a consistent dissociation between outside-in and inside-out focused behaviors, profiles varying in the association of home literacy behaviors would emerge. Although the exploratory nature of this study precluded anticipation of every cluster profile we might find, building on prior home literacy studies and the findings of Brenner and Fox (1999), we hypothesized finding support for (a) a cluster with a high outside-in, low inside-out profile (i.e., high on shared book reading but low on code-related activities) composed predominantly of middle- and upper-middleincome families, and (b) a cluster with a profile of low frequency on both types of activities that includes a disproportionate number of families from lower to lower middle-income backgrounds, given the home literacy-SES associations found in previous studies. 


\section{METHOD}

\section{Participants}

Participants in this study were the primary caregivers for children attending preschool or kindergarten programs between 1995 and 2005. These children were included within a number of different assessment and intervention studies that focused on emergent literacy skills. The children ranged in age from 2 to 5 years at the time of initial recruitment, and they attended a wide variety of preschool center settings, including private centers, churchbased programs, Head Start, and subsidized child care. In cases where children were followed longitudinally and caregivers were asked to complete the survey form on multiple occasions, the first completed form was used for this study. The rare exception to this occurred when the first survey was not adequately completed (e.g., included more than $10 \%$ missing data).

From an initial pool of more than 1,300 , surveys were included in the final sample if the target child was no older than 5 years at the time of survey completion and included valid responses to questions regarding income and maternal education. Given the item-level nature of these analyses, we elected to follow a conservative approach to missing data and excluded a small number of cases $(n=20)$ missing more than three responses on the variables selected for use in the analyses. Ten cases were dropped for being multivariate or extreme univariate outliers. In total, the final sample included 1,044 caregiver-completed surveys. The very small number (i.e., less than $2 \%$ ) of remaining missing data points were replaced by the item's median value.

Mothers completed the overwhelming majority of the surveys (i.e., 91\%). The rest were completed by fathers, grandparents, or other guardians. The demographic characteristics for this sample of respondents are summarized in Table 1. On average, the caregivers had more than a high school education and had household incomes that ranged from below $\$ 10,000$ to more than $\$ 250,000$ per year. Most respondents lived with a spouse or partner, had multiple children, and worked outside the home. The children of these respondents ranged in age from 2 to 5 years $(M=49.32, S D=9.36)$ and included $48.9 \%$ boys. Consistent with the ethnic composition of the surrounding community, the ethnic backgrounds of the children included approximately 58\% Caucasian; 39\% African American; and 3\% other backgrounds, including Hispanic, Asian, and Native American. Data were not collected separately on the ethnic background of the survey respondents, so this sample's ethnic composition may vary slightly from the proportions listed, if one assumes that some small percentage of children come from multiethnic homes or were adopted by parents of a different ethnic background.

\section{Measures}

Home literacy questionnaire-The home literacy questionnaire survey included a series of questions about the home situation including income, caregiver education, presence of other children in the home, presence of father or paternal figure in the home, and other related questions. Respondents then completed a series of questions regarding the home literacy environment, including number of children's books owned, frequency of shared 
reading with child, frequency of literacy teaching, frequency of library visits, and other questions about home literacy activities and child interests. For example, respondents were asked to rate how much their children enjoyed being read to by themselves or others in the home (i.e., four choices from "a little" to "loves it"). Respondents also completed questions about their children's television watching habits. As is discussed in more detail next, groups of respondents received two slightly different versions of this measure based on whether their child was recruited from Head Start and similar subsidized childcare centers or from childcare centers serving a more affluent population. The version completed by the respondents from lower-income homes included only multiple-choice formatting or Likerttype scales, whereas the alternate version included a few open-ended question formats for some of the same questions.

To combine data across the two survey versions, several questionnaire items were rescaled on one or both versions. For both questions regarding how often per week the child was read to by the respondent or by others in the home, the open-ended responses were recoded onto the Likert-type scale version where choices ranged from 0 (never) to 6 (almost daily). Openended responses that were greater than 6 , reflecting children being read to daily or more often per week, were recoded as either 7 or 8 , depending on whether they fell above or below a clear distributional split in the data. Questions regarding total and educational television viewing were asked in both versions; the lower income version asked separately for weekday and weekend average hours, whereas the other version asked for average hours per week. The weekday and weekend responses on the former version were averaged to align with the single response on the latter version; overall television viewing and educational television viewing hours were maintained as distinct variables for the subsequent analyses. For a question regarding number of children's books owned, the lower income version included Likert-type scale choices from 0 (none) to 8 (201 or more) in increments of 20 from 1 to 100 and in increments of 50 thereafter. The open-ended responses on the other version were recoded to fit one of these eight choices. On both versions, caregivers were asked identical additional questions regarding their own reading ability (i.e., selecting from among four choices from poor to outstanding), and their current level of stress (i.e., selecting from among four choices from normal to very high).

Finally, whereas the question regarding annual income was open-ended on one version, it was posed as a $0(\$ 0-\$ 5,000)$ to 5 (more than $\$ 25,000)$ Likert-type scale on the other version. Both versions were equated by rescaling responses onto a 10-item scale with anchors ranging from $1(\$ 0-15,000)$ to 10 (more than $\$ 200,000)$. All respondents who answered 5 (more than $\$ 25,000$ ) on the lower income version were assigned a 3 on the new scale, which represented income from $\$ 26,000$ to $\$ 34,000$ annually. This decision was made based on the recruitment of these participants from Head Start and similar subsidized child care centers, all of which have eligibility requirements of income either at or below the poverty level (Head Start) or no greater than $150 \%$ of the poverty level (subsidized child care), making it unlikely that the rescaling substantially undervalues the home incomes of these families. Information from the Consumer Price Index-based purchasing power calculations (e.g., http://www.measuringworth.com) and the Census Bureau (2008) indicated that the ranges included in the aforementioned income scale accounted for variations in the 
value of family income across time and did not meaningfully affect the poverty threshold used to classify some lower income households.

\section{Procedures}

Parents were mailed or hand delivered the parent survey materials within a few months of completing initial consent forms for their and their child's participation. Surveys were returned by mail or collected at the children's preschool programs. Depending on the project in which the family participated, some parents received small incentives to return the forms, such as $\$ 5$ or $\$ 10$ gift certificates to local restaurants. Parents completed the measures described earlier as part of a larger packet that included several additional instruments describing their child's temperament, activity preferences, and behavior problems.

\section{RESULTS}

\section{Preliminary Analyses}

Means, standard deviations, and response ranges for 13 home literacy survey questions for the entire sample of 1,044 respondents are shown in Table 2. In general, the caregivers began reading to their child when the child was around 6 months old, read with the child four to five times per week, and owned more than 60 children's books. The caregivers also reported engaging in letter-focused activities once or twice a week, on average. These means, however, are not evocative of the wide ranges and sizable standard deviations within the sample, indicating large variations for virtually all questions. Bivariate correlations for the 12 variables used in the cluster analyses presented next are shown in Table 3. These results indicate low to moderate relations among most variables. Given the large sample size, even relatively small correlations were statistically significant. Of particular note is the dissociation between rates of shared reading with the children and rates of intentional teaching of the alphabet or playing alphabet games. This low relation does not appear to apply as much to activities such as pointing out words in the environment or playing with rhymes, behaviors that may seem more natural and thus more appropriate to these caregivers.

\section{Cluster Analyses}

The full sample was subdivided into three random subgroups of approximately 350 participants each for the cluster analyses. In each group, a hierarchical agglomerative cluster analysis using Ward's method and squared Euclidean distance was performed on a group of 12 variables selected to be representative of multiple aspects of the home literacy environment (Milligan \& Cooper, 1987). These included all variables shown in Table 2 except for frequency of visiting the library. Four variables reflect an inside-out focus on activities intended to teach children the "code" of reading, namely, pointing out words, playing rhyming and alphabet games, and directly teaching the alphabet. Six variables reflect an outside-in focus on activities representing the act of reading, namely, both variables about reading to the child, children's independent looking at books (a kind of "emergent reading"), child's age at first shared reading experience, number of books owned, and the frequency at which the child observes others in the household reading. The two variables related to frequency of watching television were included as representatives of 
other typical daily activities engaged in by the children that may be educationally relevant (watching educational television) or likely detracting from educational opportunities (watching other kinds of television). The correlational analyses presented earlier indicated that none of these variables were highly correlated, meaning there was minimal concern regarding multicollinearity among the clustering variables. A distance measure of similarity (i.e., squared Euclidean) was chosen to reflect distinctions in both profile and magnitude on the clustering variables (DiStefano \& Kamphaus, 2006; Romesburg, 2004). All clustering was performed on standardized variables using SAS (SAS Institute, 2004). Ward's method was chosen as it has a record of being one of the clustering techniques that yields consistently reliable clusters (Breckenridge, 2000; Morey, Blashfield, \& Skinner, 1983).

In all three samples, these analyses independently yielded a solution supportive of three distinct clusters, based on dendrogram inspection and changes in the clustering coefficient, pseudo- $F$ and pseudo $t^{2}$ (Hair, Anderson, Tatham, \& Black, 1998; Romesburg, 2004; SAS Institute, 2004). In all instances, each cluster represented at least $21 \%$ of the respondents within the subsample, and each of the three clusters showed a comparable profile pattern within each of the three subsamples, demonstrating independent replication of the cluster solution (Breckenridge, 2000). To increase the ease with which the cluster solution could be described and externally validated, the three subsamples were recombined and the cluster analyses conducted a final time on the entire sample. Again, the same three-cluster solution appeared to best fit the data. Further support for this solution was that under a four-cluster solution the fourth cluster included just 42 respondents (i.e., $4 \%$ of the sample). Table 4 presents the means and standard deviations for the 12 clustering variables for each cluster. As expected, one-way analyses of variance indicated that every one of these 12 variables yielded a significant mean difference between two, or in some cases all three, of the cluster groups. For each post hoc comparison, a Bonferroni correction was used to set a minimally acceptable error rate of $p<.01$.

\section{Cluster Descriptions}

Inspection of the cluster profiles of both the raw (see Table 4) and standardized (see Figure 1) variables and the focus on the theoretically relevant groupings of outside-in and insideout related variables led to the naming of the clusters as being high or low, relative to one another and the sample average on these two areas. As can be seen in Figure 1, the three clusters were relatively well differentiated with respect to this characterization. The profile for all three clusters on the three clustering variables that depict frequency of home literacy behaviors per week is shown in Figure 1. The profile for the five variables for which responses ranged from never to daily is also shown in Figure 1. Cluster $1(n=357)$, the "low-low" group, represented $34.2 \%$ of the sample and was characterized by having low or moderate relative frequencies both on the outside-in, shared reading and other book-related variables and on the inside-out code-instruction variables. This cluster also was notable in that children watched a relatively moderate amount of television (between the other two clusters) but saw the least educational television as a proportion of total daily television viewing (see Table 4). 
Cluster $2(n=344)$, represented 33\% of the total sample and was labeled "high-high" because they had high frequencies on both outside-in and inside-out domain variables. They had a significantly earlier onset of reading to their children than did members of both other clusters, and significantly higher frequencies than both other clusters on all of the variables representing the outside-in aspect of early literacy. In contrast, the children of caregivers in this group watched significantly less television than did children of caregivers in either other group. For the inside-out variables, Cluster 2's frequency of playing alphabet games and teaching the letters was comparable to that of Cluster 3 but significantly higher than that for Cluster 1. Cluster 2 caregivers had a higher frequency than did members of both other clusters for rhyming activities and pointing out words in the environment (see Figure 1).

Finally, Cluster 3 ( $n=343)$, representing $32.9 \%$ of the sample, was characterized as "lowhigh." These respondents were relatively and significantly low on outside-in behaviors of book ownership, reading onset, and both of the shared reading variables but were relatively high, in one case the highest, on the alphabet-related inside-out instructional variables. Their scores were midway between the other two clusters, significantly different from both, on rhyming and pointing out words. Somewhat surprisingly, despite being quite low on the dyadic reading variables and owning the fewest books, this cluster reported moderately high frequencies of children independently looking at books. Cluster 3 also distinguished itself by being significantly higher than both other clusters on the television watching variables but was equivalent to Cluster 2 on the proportion of educational television viewed as a percentage of the total daily amount.

\section{Confirmatory Analyses}

As a secondary check on the stability and validity of the three-cluster solution, a discriminant analyses was run using the clustering variables to determine whether cluster members would be correctly classified. The results of this analyses indicated that $73.9 \%$ of Cluster $1,85.5 \%$ of Cluster 2, and $82.8 \%$ of Cluster 3 members were correctly classified by the two discriminant functions. The overall classification rate was $80.7 \%$; using leave-oneout analyses, the rate was comparable at $79.9 \%$. These latter analyses involve a jackknifing procedure in which each case is classified based on the functions derived from all other cases and represent a correction for bias in the initial hit rate (Huberty, 1994).

Once the three-cluster solution was determined and the clusters labeled with theoretically meaningful identifications, the clusters were compared on variables not included within the clustering. These included demographic variables such as income, mother's education level, presence and number of other children in the family, whether the caregiver lived with a spouse or partner, and the caregiver's self-reported reading skills. The external variables also included caregiver's level of stress, frequency of library visits with child, and caregiver report of how much the child enjoyed being read to. A priori planned analysis of variance contrasts were conducted between all paired cluster groups. As shown in Table 5, two or more of the clusters differed significantly on most of these variables. For example, on the two socioeconomic indicators - maternal education and household income-the average for Cluster 2 high-high was significantly higher than both other clusters, and Clusters 1 low-low and 3 low-high also differed significantly. Likewise, caregivers in Cluster 2 high-high were 
significantly more likely to live with a spouse or partner than caregivers in both the other clusters, who also differed on this characteristic. Caregivers in Cluster 2 also reported having significantly fewer children than those in Cluster 1. Caregivers in this high-high cluster also indicated that their children enjoyed being read to more than the children of caregivers in the other clusters, which perhaps is explained by the fact that these caregivers reported significantly, albeit modestly, stronger reading skills than did all other caregivers, or by the greater frequency of shared reading events within these households relative to all others.

Consistent with their high-high home literacy profile, Cluster 2 members visited the library with their children significantly more often than members of both the other clusters, which were comparable on this variable. Finally, there were significant differences in ethnic characteristics for all clusters, $\chi^{2}(4, N=1,044)=280.49, p<.001$. Cluster 3 was almost 74\% African American, with 23\% Caucasian and 3\% other ethnicities. In contrast, Cluster 2 included only $17 \%$ African American respondents, with $81 \%$ Caucasian and approximately $2 \%$ other ethnicities. Cluster 1 was still, although somewhat less so, disproportionate, including 26\% African Americans, 71\% Caucasians, and 3\% other ethnicities. No significant differences were found for the proportions of male and female children across the three clusters, although the percentage of girls in Cluster 3 was slightly disproportionate at $56 \%$. No significant differences were found in child age at the time of caregiver report.

The final analysis investigated whether reported caregiver characteristics could correctly predict the cluster membership for the caregivers. A discriminant analysis was conducted with income, education, ethnicity, caregiver reading skills, living with a partner, and number of other children included as predictors. Wilks's lambda indicated that two discriminant functions were significant at the $p<.001$ level, that is, overall $\ddot{\mathrm{E}}=0.67, \chi^{2}(12, N=1,042)=$ 413.38; residual $\ddot{\mathrm{E}}=0.98, \chi^{2}(5,1,042)=24.47$, with the first function being most strongly related to ethnicity and the two SES variables. The second discriminant function was most strongly associated with caregiver reading skill and number of other children. Correct classification hit rates and misclassification rates are shown in Table 6. Inspection of the misclassifications for Cluster 1 suggested that a substantial number of caregivers with moderately high SES backgrounds, which predicts a high-high classification, were "underperforming" in terms of actual home literacy behaviors. In contrast, 27\% of Cluster 2 members were misclassified as belonging to Cluster 1, suggesting that a similar number of respondents with midrange SES characteristics may have been "overperforming" in terms of actual home literacy behaviors. Another $27 \%$ of Cluster 1 members were misclassified as belonging to Cluster 3, likely be- cause of SES factors. No other misclassification percentage exceeded $16 \%$. These results clearly suggest that there are unmeasured factors that contributed to cluster membership, perhaps related to parental beliefs, time and stress management skills, and familiarity with child development.

\section{DISCUSSION}

\section{Theoretical Implications}

These analyses yielded a three-cluster solution that was distinguishable on the outside-in and inside-out related clustering variables and also on an array of demographic and other self- 
report survey responses related to literacy activities and home environment. In both the correlations and the clustering profiles, these results were consistent with the relative independence and differential impacts of different home literacy activities as found by Sénéchal (e.g., Sénéchal et al., 1998) and others (e.g., de Jong \& Leseman, 2001; Evans et al., 2000) and with the differentiation between meaning-focused and code-focused activities in early childhood classrooms (Connor, Morrison, \& Petrella, 2004). Further, the results are consistent with the literature in finding a significant association between SES and home literacy activities, in terms of both caregiver education and family income. In keeping with predictions, a group of families was determined to have a relatively low level of home literacy interactions with their young child; although this group did not, as was predicted, consist primarily of families from lower SES contexts. Notably, the hypothesized cluster of high outside-in, but low inside-out was not specifically recovered in these data.

These results indicated that relations between types of behaviors, and SES contexts, are more complex and less linear than is sometimes assumed. The finding that the lowest and highest SES groups (i.e., Cluster 3 and Cluster 2) were quite different in terms of outside-in activities, but comparable, and relatively high, on their inside-out activities, contradicts older studies indicating that instructional activities intended to foster alphabet knowledge and phonological awareness are more prevalent or accepted in low-income households (e.g., Rosier \& Corsaro, 1993; Stipek et al., 1992). Cluster 3 was notable in its low-high pattern of having a relatively greater focus on inside-out, code-related activities than on shared reading and literacy environment activities, potentially because of SES-related limitations on time and discretionary income to spend on books. Whereas this greater focus on code-related activities often is viewed, negatively, as a characteristic of less educated parents, in this sample both the least and the most educated caregivers showed the most similar profiles with respect to these inside-out-related activities.

No cluster precisely fit the model of high outside-in but low inside-out focused activity patterns that was predicted. The cluster that came the closest to this predicted profile was Cluster 1, with moderate to low caregiver outside-in shared reading frequencies and both relative and absolute low frequencies on all inside-out, code-related variables. Some prior research and theory (e.g., DeBaryshe \& Binder, 1994) would have predicted that the welleducated, upper-middle-class families in Cluster 2 would be the most likely to adhere to a high outside-in but low inside-out profile. This prediction was fueled by the idea that these parents would be those most likely exposed to extreme, and somewhat misconceived interpretations of developmentally appropriate practice (DAP) that have led some educators to disavow teacher- or parent-directed learning interactions and disapprove of teachers who included code-focused instruction in their early childhood classrooms (Bredekamp, 1991; McGill-Franzen, Langford, \& Adams, 2002; Purcell \& Rosemary, 2007). However, although their mean frequency ratings for all outside-in variables indicated that they were enacting these behaviors at least three times a week, Cluster 2 reported also engaging in the inside-out focused behaviors at least once a week, on average. In contrast to an aversion to letter and sound-manipulation teaching, the relatively well-educated and affluent caregivers within this cluster appear to have a desire to provide their children with a well-rounded and rich literacy environment that encourages learning of many emergent literacy skills. Holloway, Rambaud, Fuller, and Eggers-Pierola (1995) also reported findings contradicting 
a purely linear relation between parental beliefs and income. In their ecological study with low-income mothers of young children, parents held a wide range of beliefs about appropriate practices, representing multiple types of interactions and activities, including those typically ascribed to more affluent parents. The current results also align with research on parental beliefs regarding kindergarten readiness indicating a desire for children to develop skills in both academic and social domains (e.g., Diamond et al. 2000; KnudsenLindauer \& Harris, 1989).

The finding that caregivers in two of the three clusters reported engaging in inside-out related games and activities frequently with their young children potentially reflects an increase in parental understanding of and comfort with the emergent literacy skills of phonological awareness and letter knowledge as relevant and important aspects of their children's development. Greater attention to the value of helping children acquire these foundational skills would parallel the evolution in the policy and instructional position statements of early childhood organizations such as the National Association for the Education of Young Children (NAEYC), whose DAP position statements have been highly influential on the practices and beliefs espoused within early childhood educational settings (Dickinson, 2002; McGill-Franzen et al., 2002; Purcell \& Rosemary, 2007). Early versions were quite limited in their attention to code-focused skill development in the preschool period. For example, even the revised DAP document issued in 1997 (Bredekamp \& Copple, 1997) made little or no specific reference to the importance of phonological awareness development in preschool-age children. However, the newly released NAEYC DAP statement (2009) specifically references the importance of alphabet knowledge and phonological awareness and the recent version of the NAEYC Program Accreditation Standards indicates that children should be provided with regular opportunities to develop phonological awareness and endorses the use of explicit skills instruction within an array of teaching strategies (NAEYC, 2007). Parents of many young children likely attend to the types of activities they observe in their children's early childhood classrooms. If so, then increases in developmentally appropriate inside-out focused learning interactions in preschools may be leading to increases in similar caregiver-child interactions at home.

Several relatively unique characteristics of Cluster 3 deserve further attention. This cluster was distinguishable in part by the significantly greater amount of time the children reportedly spent per day watching television. Although this report included some educational television, this time could be considered missed opportunities for parent-child interactions devoted to building either outside-in or inside-out-related literacy skills. A secondary and somewhat contradictory finding was that the rate of children independently looking at books was moderate to high in this cluster, in comparison with the other two clusters. This was despite having the lowest number of books in the home and being relatively low on the other outside-in, shared book reading activities. One way to interpret both of these findings may be to consider the independent versus dyadic nature of activities. Our speculation is that children in this cluster may have spent a proportionately greater amount of time watching television and playing with books without parental mediation because of the more limited time caregivers may have had to devote to dyadic interactions. This would be consistent with the results indicating a greater number of children in the household and, simultaneously, a greater number of single-parent households within this 
cluster, relative to the other two. Future research is needed on families that fit this profile to explore the constraints that resource limitations and family structure may place on how well parents are able to act on their goals and intentions related to children's learning opportunities in the home environment (Lareau, 2003).

\section{Quality of Interactions}

Despite having average demographic characteristics that were solidly middle income, a large number of families fell into the low-low cluster who displayed moderate levels of caregiverchild shared reading, but significantly and substantially low frequencies of virtually all other home literacy activities relative to the other clusters (i.e., caregivers identified as "underperforming" relative to family SES). Similarly, there were a number of families in Cluster 2 who could be considered "overperformers" relative to their SES profiles. The fact that these patterns of behavior could not be well understood in the context of typical social capital variables such as income, education, and family structure suggests that qualities of these families not captured by these data, such as parental belief systems, family dynamics, and intergenerational modeling, are likely contributing factors that would augment the predictive power of SES status variables alone (Brooks-Gunn \& Markman, 2005; Phillips \& Lonigan, 2005). These results are consistent with the work of Farver et al. (2006) and others (e.g., Foster et al., 2005; Holloway et al., 1995) who found considerable variability within income strata in parental behaviors and attitudes related to early literacy.

An acknowledged limitation of these findings is that knowledge of the frequency of various behaviors cannot distinguish their quality. There is no way to know, for example, whether the letter-related instructional activities conducted by Cluster 3 caregivers were comparable in affective tone and interactive engagement to those engaged in by Cluster 2 caregivers. For example, one caregiver may play interactive games with letters to teach her child the alphabet, whereas another caregiver may have her child recite letters on flashcards. If the frequency of these activities were comparable, they were indiscriminable on the current rating scales. Likewise, the relatively low frequencies of all types of home literacy behaviors reported by Cluster 1 may mask high-quality and instructionally potent learning opportunities for their children. Given this lack of quality data, these results also underscore the potential mischaracterization of all inside-out focused instruction as negative, developmentally inappropriate, or as antithetical to a desire to support a "literacy as entertainment" philosophy. The reality may be much more nuanced than that, because whether a type of activity has a net positive or negative influence theoretically is the result of an interaction between the type of focus, the affective tone of the interaction, and of the broader context (i.e., whether other domains also are attended to regularly). This is in keeping with Darling and Steinberg's (1993) differentiation between parenting style and parenting practices and with the idea that the success of these interactions is reciprocally determined by the responses of both parents and children (Harrist \& Waugh, 2002; Kochanska, 1997). Moreover, research giving attention to the socioemotional aspects of home language and literacy interactions, albeit limited, does support the influence of the tone and warmth of such interactions (e.g., Berlin, Brooks-Gunn, Spiker, \& Zaslow, 1995; Britto \& Brooks-Gunn, 2001; Bus \& van IJzendoorn, 1995, 1997; de Jong \& Leseman, 2001; Landry, Smith, Swank, Assel, \& Vellet, 2001). 


\section{Need for Future Research}

One avenue in need of significant research is the question of whether outside-in and insideout home emergent literacy behaviors differentially influence children's motivation to learn to read and for school in general. It may be, as noted by Phillips and Lonigan (2005), that effect on skill and motivation are disproportionate for inside-out and outside-in behaviors, respectively. That is, more traditional outside-in shared reading behaviors may indeed have the stronger impact on children's motivation toward becoming a reader (e.g., Baker, 2003; Morrow \& Young, 1997; Sonnenschein \& Munstermann, 2002). In contrast, the transmittal of beliefs regarding the importance of school and the acquisition of academic content might segregate with inside-out focused behaviors (e.g., Foy \& Mann, 2003; Hoover-Dempsey et al., 2005; Sénéchal et al., 1998). This latter pathway would be consistent with research indicating that more academically related activities are part of how parents convey their "press for achievement" to their children (e.g., Hammer, Miccio, \& Wagstaff, 2003; Hess, Holloway, Dickson, \& Price, 1984). Findings in support of this multiple-pathway theory would argue for advocacy and support of both types of caregiver-child interactions during the preschool years, particularly for children whose family background puts them at risk for skill deficits relative to more advantaged children. Recent work by Dearing and colleagues (Dearing, McCartney, Weiss, Kreider, \& Simpkins, 2004) supports this position, in that they found that parental involvement in kindergarten had a significantly greater impact on children's literacy performance within families from lower income strata. Notably, children's feelings about the importance of school and learning mediated this relation. Our current research efforts include a detailed investigation into caregiver beliefs, stylistic characteristics, and motivations for their own behavioral choices related to how they structure the home literacy environment. Further, longitudinal work is needed to investigate the relation between frequency and type of parental interactions with their children during the preschool age, and these parents' levels and types of school involvement once their children reach the age of formal schooling (e.g., Englund, Luckner, Whaley, \& Egeland, 2004).

There is a need to replicate and extend this research with families of varied cultural backgrounds, in particular to explore whether cultural values are mediating parental choices regarding activities in which they engage their child. These investigations are especially relevant given the literature suggesting that by culture, degree of acculturation, and SES parents often differ in how much they believe it is their role to do any actual teaching with their child and the role of siblings and extended family members in supporting children's learning (e.g., Goldenberg, 1987; Lareau, 2003; Rodriguez \& Olswang, 2003). Cultural values influence parents' perspectives on the appropriateness of home educational activities (Farver et al., 2006; Goldenberg, 1987; Zea, Quezada, \& Belgrave, 1994). Studies show cultural mediation of parental beliefs regarding child-directed speech and verbal instructions (e.g., Johnston \& Wong, 2002; Qualls, 2001; Zayas \& Solari, 1994), in the degree of directedness parents display (e.g., Chao, 1996; Coolahan, McWayne, Fantuzzo, \& Grim, 2002; Kinlaw, Kurtz-Costes, \& Goodman-Fraser, 2001; Vigil, 1999), and in parent's selfefficacy related to helping their children learn (e.g., Drummond \& Stipek, 2004; Lareau \& Shumar, 1996). 


\section{Study Limitations}

Although illuminating as to the caregivers' behavioral patterns, this study had some limitations. Cluster analysis is by design an exploratory tool to gain descriptive insight into within-participant patterns. This study's use of the three random subsamples for internal replication does strengthen its credibility, but independent replication with novel samples and using other clustering techniques, or similar, more confirmatory methods, such as latent class analyses is clearly warranted. Moreover, because of its descriptive nature, our study cannot speak directly to causal processes or to the specific, proximal mechanisms of how parent choices affect the development of early language and literacy skills. However, we do believe that a strength of cluster analyses and of these results is that they call much needed attention to the idea that parents' decisions about which types of behaviors to adopt are not made in isolation but in reliable patterns, and that these patterns are influenced by their daily life circumstances, access to resources, and likely their beliefs about their role as a parent (Hoover-Dempsey et al., 2005). Given these multiple influences, research is needed to explore whether the optimal home literacy environment for one parent-child dyad, with respect to meaningful differences in children's performance on literacy and language measures during and after the preschool period, may be distinct from that which is optimal for another.

The age range of the children at the moment of caregiver report can be seen as both a benefit and a detriment. The home literacy activities that a caregiver might have prioritized when their child was younger, or conversely, that they intend to initiate when their child is somewhat older, are not captured by these data (Goodsitt et al., 1988). However, the several year spread in child age does capture the full preschool context and as previously noted, there were no differences in the proportion of children at the younger or older points in this continuum across the three clusters. This finding suggests that whereas within-child there likely are alterations in both parental and child behaviors and priorities across a developmental trajectory, the current data capture the relevant between-child phenomena irrespective of age. Longitudinal studies are warranted in which caregivers report on a full array of home literacy behaviors at multiple points across their child's early development. As well, use of parent self-reports, although needed to achieve the substantial sample size, does raise questions about whether parents were accurately reporting their behaviors. Whereas the range of responses and the quite low frequencies reported for some activities argues against the likelihood of widespread inflation, follow-up studies using observational methods would be an important way to independently validate the parent reports.

\section{Applications and Conclusions}

In summary, our results, although preliminary, are consistent with the theory suggesting differential focus and interest among parents in participating in shared reading versus other more code-related instructional activities with their preschool-age children. Research is needed to replicate this finding and to investigate what individual and sociocultural factors might contribute to the three distinct cluster membership profiles. Specifically, studies should explore what factors might increase the participation in literacy-related activities among the caregivers within the low-low profile group. Such investigations would allow for better differentiation of school outreach and other intervention efforts to appeal to the 
interests and unique needs of individual families. Ultimately, this research needs to determine how, and by what specific mechanisms, the different patterns of home literacy behaviors affect the children's current and future literacy achievement. Greater understanding of these mechanisms can support the development of new intervention and instructional programs at home and at school to help close the gap between young children with and without strong early literacy skills.

\section{ACKNOWLEDGMENTS}

Preparation of this work and some of the studies reported herein was supported, in part, by grants from National Institute of Child Health and Human Development (HD38880, HD36067, HD36509, HD30988); the Administration for Children, Youth, and Families (90YF0023); the National Science Foundation (REC-0128970); and the Institute of Education Sciences (R305J030093, R305B04074). Views expressed herein are solely those of the authors and have not been cleared by the grantors.

\section{References}

Baker L. The role of parents in motivating struggling readers. Reading and Writing Quarterly. 2003; 19:87-106.

Baker, L.; Fernandez-Fein, S.; Scher, D.; Williams, H. Home experiences related to the development of word recognition. In: Metsala, JL.; Ehri, LC., editors. Word recognition in beginning literacy. Mahwah, NJ: Erlbaum; 1998. p. 263-287.

Baker L, Scher D, Mackler K. Home and family influences on motivations for reading. Educational Psychologist. 1997; 32:69-82.

Baumwell L, Tamis-LeMonda CS, Bornstein MH. Maternal verbal sensitivity and child language comprehension. Infant Behavior and Development. 1997; 20:247-258.

Berlin LJ, Brooks-Gunn J, Spiker D, Zaslow MJ. Examining observational measures of emotional support and cognitive stimulation in black and white mothers of preschoolers. Journal of Family Issues. 1995; 16:664-686.

Bowey JA. Socioeconomic status differences in preschool phonological sensitivity and first-grade reading achievement. Journal of Educational Psychology. 1995; 87:476-487.

Bradley RH, Corwyn RF. Socioeconomic status and child development. Annual Review of Psychology. 2002; 53:371-399.

Breckenridge JN. Validating cluster analysis: Consistent replication and symmetry. Multivariate Behavioral Research. 2000; 35:261-285.

Bredekamp S. Redeveloping early childhood education: A response to Kessler. Early Childhood Research Quarterly. 1991; 6:199-209.

Bredekamp, S.; Copple, C. Developmentally appropriate practice in early childhood programsRevised edition. Washington, DC: National Association for the Education of Young Children; 1997.

Brenner V, Fox RA. An empirically derived classification of parenting practices. The Journal of Genetic Psychology. 1999; 160:343-356.

Britto PR, Brooks-Gunn J. Beyond shared book reading: Dimensions of home literacy and low-income African American preschooler's skills. New Directions for Child and Adolescent Development. 2001; 92:73-89. [PubMed: 11468868]

Brooks-Gunn J, Markman LB. The contribution of parenting to ethnic and racial gaps in school readiness. The Future of Children. 2005; 15:139-168. [PubMed: 16130545]

Burgess SR. The influence of speech perception, oral language ability, the home literacy environment, and pre-reading knowledge on the growth of phonological sensitivity: A one-year longitudinal investigation. Reading and Writing. 2002; 15:709-737.

Burgess SR, Hecht SA, Lonigan CJ. Relations of home literacy environment to the development of reading-related abilities: A one-year longitudinal study. Reading Research Quarterly. 2002; 37:408-426. 
Bus AG, van IJzendoorn MH. Mothers reading to their three-year-olds: The role of mother-child attachment security in becoming literate. Reading Research Quarterly. 1995; 40:998-1015.

Bus AG, van IJzendoorn MH. Affective dimension of mother-infant picturebook reading. Journal of School Psychology. 1997; 35:47-60.

Bus AG, van IJzendorn MH, Pellegrini AD. Joint book reading makes for success in learning to read: A meta-analysis on intergenerational transmission of literacy. Review of Educational Research. 1995; 65:1-21.

Chaney C. Language development, metalinguistic awareness, and emergent literacy skills of 3-yearold children in relation to social class. Applied Psycholinguistics. 1994; 15:371-394.

Chao RK. Chinese and American mothers' beliefs about the role of parenting in children's school success. Journal of Cross-Cultural Psychology. 1996; 27:403-423.

Christian K, Morrison FJ, Bryant FB. Predicting kindergarten academic skills: Interactions among child care, maternal education, and family literacy environment. Early Childhood Research Quarterly. 1998; 13:501-521.

Connor CM, Morrison FJ, Petrella JN. Effective reading comprehension instruction: Examining child $\times$ instructor interactions. Journal of Educational Psychology. 2004; 96:682-698.

Coolahan K, McWayne C, Fantuzzo J, Grim S. Validation of a multidimensional assessment of parenting styles for low-income African American families with preschool children. Early Childhood Research Quarterly. 2002; 17:356-373.

Danis A, Bernard JM, Leproux C. Shared picture-book reading: A sequential analysis of adult-child interactions. British Journal of Developmental Psychology. 2000; 18:369-388.

Darling N, Steinberg L. Parenting style as context: An integrative model. Psychological Bulletin. 1993; 113:487-496.

Dearing E, McCartney K, Weiss HB, Kreider H, Simpkins S. The promotive effects of family educational involvement for low-income children's literacy. Journal of School Psychology. 2004; 42:442-460.

DeBaryshe BD. Maternal belief system: Linchpin in the home reading process. Journal of Applied Developmental Psychology. 1995; 16:1-20.

DeBaryshe BD, Binder JC. Development of an instrument for measuring parental beliefs about reading aloud to young children. Perceptual and Motor Skills. 1994; 78:1303-1311.

de Jong PF, Leseman PPM. Lasting effects of home literacy on reading achievement in school. Journal of School Psychology. 2001; 39:389-414.

Diamond KE, Reagan AJ, Bandyk JE. Parents' conceptions of kindergarten readiness: Relationships with race, ethnicity, and development. Journal of Educational Research. 2000; 94:93-100.

Dickinson DK. Shifting images of developmentally appropriate practices as seen through different lenses. Educational Researcher. 2002; 31:26-32.

DiStefano C, Kamphaus RW. Investigating subtypes of child development: A comparison of cluster analysis and latent class cluster analysis in typology creation. Educational and Psychological Measurement. 2006; 66:778-794.

Drummond KV, Stipek D. Low-income parents' beliefs about their role in children's academic learning. The Elementary School Journal. 2004; 104:197-213.

Dunning DB, Mason JM, Stewart JP. Reading to preschoolers: A response to Scarborough and Dobrich (1994) and recommendations for future research. Developmental Review. 1994; 14:324339.

Elkind, D. Miseducation: Preschoolers at risk. New York: Knopf; 1987.

Englund MM, Luckner AE, Whaley GJL, Egeland B. Children's achievement in early elementary school: Longitudinal effects of parent involvement, expectations, and quality of assistance. Journal of Educational Psychology. 2004; 96:723-730.

Evans MA, Shaw D, Bell M. Home literacy activities and their influence on early literacy skills. Canadian Journal of Experimental Psychology. 2000; 54:65-75. [PubMed: 10881391]

Farver JM, Xu Y, Eppe S, Lonigan CJ. Home environments and young Latino children's school readiness. Early Childhood Research Quarterly. 2006; 21:196-212. 
Federal Interagency Forum on Child and Family Statistics. Washington, DC: Author; 2003. America's children: Key national indicators of well-being. from http://www.childstats.gov [Retrieved December 8, 2003]

Feitelson D, Goldstein Z. Patterns of book ownership and reading to young children in Israeli schooloriented and nonschool-oriented families. Reading Teacher. 1986; 39:924-930.

Fish M, Pinkerman B. Language skills in low-SES rural Appalachian children: Normative development and individual differences, infancy to preschool. Applied Developmental Psychology. 2003; 23:539-565.

Foster MA, Lambert R, Abbott-Shim M, McCarty F, Franze S. A model of home learning environment and social risk factors in relation to children's emergent literacy and social outcomes. Early Childhood Research Quarterly. 2005; 20:13-36.

Foy JG, Mann V. Home literacy environment and phonological awareness in preschool children: Differential effects for rhyme and phoneme awareness. Applied Psycholinguistics. 2003; 24:5988.

Frijters JC, Barron RW, Brunello M. Direct and mediated influences of home literacy and literacy interest on prereaders' oral vocabulary and early written language skill. Journal of Educational Psychology. 2000; 92:466-477.

Goldenberg CN. Low-income Hispanic parents' contributions to their first-grade children's wordrecognition skills. Anthropology \& Education Quarterly. 1987; 18:149-179.

Goodsitt J, Raitan JG, Perlmutter M. Interaction between mothers and preschool children when reading a novel and familiar book. International Journal of Behavioral Development. 1988; 11:489-505.

Haden CA, Reese E, Fivush R. Mothers' extratextual comments during storybook reading: Stylistic changes over time and across text. Discourse Processes. 1996; 21:135-169.

Hair, JF.; Anderson, RE.; Tatham, RL.; Black, WC. Multivariate data analyses. Upper Saddle River, NJ: Prentice Hall; 1998.

Hammer CS, Miccio AW, Wagstaff DA. Home literacy experiences and their relationship to bilingual preschoolers' developing English literacy abilities: An initial investigation. Language, Speech, and Hearing Services in the Schools. 2003; 34:20-30.

Hammett LA, van Kleeck A, Huberty CJ. Patterns of parents' extratextual interactions during book sharing with preschool children: A cluster analysis study. Reading Research Quarterly. 2003; 38:442-468.

Harrist AW, Waugh RM. Dyadic synchrony: Its structure and function in children's development. Developmental Review. 2002; 22:555-592.

Hecht SA, Burgess SR, Torgesen JK, Wagner RK, Rashotte CA. Explaining social class differences in growth of reading skills from beginning kindergarten through fourth-grade: The role of phonological awareness, rate of access, and print knowledge. Reading and Writing: An Interdisciplinary Journal. 2000; 12:99-127.

Hess RD, Holloway SD, Dickson WP, Price GP. Maternal variables as predictors of children's school readiness and later achievement in vocabulary and mathematics in sixth grade. Child Development. 1984; 55:1902-1912.

Holloway SD, Rambaud MF, Fuller B, Eggers-Pierola C. What is "Appropriate Practice" at home and in child care: Low-income mothers' views on preparing their children for school. Early Childhood Research Quarterly. 1995; 10:451-473.

Hoover-Dempsey KV, Walker JMT, Sandler HM, Whetsel D, Green CL, Wilkins AS, et al. Why do parents become involved? Research findings and implications. Elementary School Journal. 2005; 106:105-130.

Huberty, CJ. Applied discriminant analysis. New York: Wiley; 1994.

Johnston JR, Wong MA. Cultural differences in beliefs and practices concerning talk to children. Journal of Speech, Language, and Hearing Research. 2002; 45:916-926.

Juel C. Learning to read and write: A longitudinal study of 54 children from first through fourth grades. Journal of Educational Psychology. 1988; 80:437-447.

Justice LM, Ezell HK. Use of storybook reading to increase print awareness in at-risk children. American Journal of Speech-Language Pathology. 2002; 11:17-29. 
Karass J, VanDeventer MC, Braungart-Ricker JM. Predicting shared parent-child book reading in infancy. Journal of Family Psychology. 2003; 17:134-146. [PubMed: 12666469]

Kinlaw CR, Kurtz-Costes B, Goodman-Fraser J. Mother's achievement beliefs and behaviors and their children's school readiness: A cultural comparison. Journal of Applied Developmental Psychology. 2001; 22:493-506.

Knudsen-Lindauer SL, Harris K. Priorities for kindergarten curricula: Views of parents and teachers. Journal of Research in Childhood Education. 1989; 4:51-61.

Kochanska G. Mutually responsive orientation between mothers and their young children: Implications for early socialization. Child Development. 1997; 68:94-112. [PubMed: 9084128]

Landry SH, Smith KE, Swank PR, Assel MA, Vellet S. Does early responsive parenting have a special importance for children's development, or is consistency across early childhood necessary? Developmental Psychology. 2001; 37:387-403. [PubMed: 11370914]

Lareau, A. Unequal childhoods: Class, race, and family life. Berkeley: University of California Press; 2003.

Lareau A, Shumar W. The problem of individualism in family-school policies. Sociology of Education. 1996; (Special/Extra Issue):24-39.

Leseman PPM, de Jong PF. Home literacy: Opportunity, instruction, cooperation, and socialemotional quality predicting early reading achievement. Reading Research Quarterly. 1998; 33:294-318.

Levy BA, Gong Z, Hessels S, Evans MA, Jared D. Understanding print: Early reading development and the contributions of home literacy experiences. Journal of Experimental Child Psychology. 2006; 93:63-93. [PubMed: 16140318]

Lonigan CJ. Reading to preschoolers exposed: Is the emperor really naked? Developmental Review. 1994; 14:303-323.

Lonigan CJ. Development, assessment and promotion of preliteracy skills. Early Education and Development. 2006; 17:91-114.

Lonigan CJ, Burgess SR, Anthony JL, Barker TA. Development of phonological sensitivity in two- to five-year-old children. Journal of Educational Psychology. 1998; 90:294-311.

Lonigan, CJ.; Dyer, SM.; Anthony, JL. The influence of the home literacy environment on the development of literacy skills in children from diverse racial and economic backgrounds; Paper presented at the annual convention of the American Educational Research Association; New York. 1996 Apr.

Lonigan, CJ.; Schatschneider, C.; Westberg, L. the National Early Literacy Panel. Report of the National Early Literacy Panel. Louisville, KY: Author; Impact of code-focused interventions on young children's early literacy skills. (in press)

Lonigan CJ, Whitehurst GJ. Examination of the relative efficacy of parent and teacher involvement in a shared-reading intervention for preschool children from low-income backgrounds. Early Childhood Research Quarterly. 1998; 17:265-292.

Lovett MW, Bordon SL, DeLuca T, Lacerenza L, Benson NJ, Brackstone D. Treating the core deficits of developmental dyslexia: Evidence of transfer of learning after phonologically- and strategicallybased reading training programs. Developmental Psychology. 1994; 30:805-822.

McCormick, CE.; Mason, JM. Intervention procedures for increasing preschool children's interest in and knowledge about reading. In: Teale, WH.; Sulzby, E., editors. Emergent literacy: Writing and reading. Norwood, NJ: Ablex; 1986. p. 90-115.

McGill-Franzen A, Langford C, Adams E. Learning to be literate: A comparison of five urban early childhood programs. Journal of Educational Psychology. 2002; 94:443-464.

Milligan GW, Cooper MC. Methodology review: Clustering methods. Applied Psychological Measurement. 1987; 11:329-354.

Morey LC, Blashfield RK, Skinner HA. A comparison of cluster analysis techniques within a sequential validation framework. Multivariate Behavioral Research. 1983; 18:309-329.

Morrow LM, Young J. A family literacy program connecting school and home: Effects on attitude, motivation, and literacy achievement. Journal of Educational Psychology. 1997; 89:736-742. 
National Association for the Education of Young Children. NAEYC Academy for Early Childhood program accreditation standards and criteria. Washington, DC: Author; 2007. from http:// www.naeyc.org/academy/NAEYCAccreditationCriteria.asp [Retrieved May 16, 2007]

National Association for the Education of Young Children. NAEYC position statement: Developmentally appropriate practice in early childhood programs serving children from birth through age 8. Washington, DC: Author; 2009. from http://www.naeyc.org/about/ positions.asp [Retrieved November 19, 2008]

Olson SL, Bates JE, Bayles K. Mother-infant interaction and the development of individual differences in children's cognitive competence. Developmental Psychology. 1984; 20:166-179.

Payne AC, Whitehurst GJ, Angell AL. The role of literacy environment in the language development of children from low-income families. Early Childhood Research Quarterly. 1994; 9:427-440.

Phillips, BM.; Lonigan, CJ. Social correlates of emergent literacy. In: Hulme, C.; Snowling, M., editors. The science of reading: A handbook. Malden, MA: Blackwell; 2005. p. 173-187.

Piotrkowski CS, Botsko M, Matthews E. Parents' and teachers' beliefs about school readiness in a high-need community. Early Childhood Research Quarterly. 2000; 15:537-558.

Potter G. Mothers' perceptions of their young children's literacy development. Australian Journal of Early Childhood. 1995; 20:7-11.

Purcell, T.; Rosemary, CA. Differentiating instruction in the preschool classroom. In: Justice, LM.; Teale, WH.; Vukelich, C.; Han, M., editors. Achieving excellence in preschool literacy instruction. New York: Guilford; 2007. p. 221-241.

Purcell-Gates V. Stories, coupons, and the TV Guide: Relationships between home literacy experiences and emergent literacy knowledge. Reading Research Quarterly. 1996; 31:406-428.

Qualls, CD. Public and personal meanings of literacy. In: Harris, JL.; Kamhi, AG.; Pollock, KE., editors. Literacy in African American communities. Mahwah, NJ: Erlbaum; 2001. p. 1-19.

Raz IS, Bryant P. Social background, phonological awareness and children's reading. British Journal of Developmental Psychology. 1990; 8:209-225.

Rodriguez BL, Olswang LB. Mexican-American and Anglo-American Mothers' beliefs and values about child rearing, education, and language impairment. American Journal of Speech-Language Pathology. 2003; 12:452-462. [PubMed: 14658997]

Romesburg, HC. Cluster analysis for researchers. Raleigh, NC: Lulu Press; 2004.

Rosier KB, Corsaro WA. Competent parents, complex lives: Managing parenthood in poverty. Journal of Contemporary Ethnography. 1993; 22:171-204.

SAS Institute Inc. SAS 9.1.3. Cary, NC: Author; 2004. [Computer software]

Scarborough HS, Dobrich W. On the efficacy of reading to preschoolers. Developmental Review. 1994; 14:245-230.

Sénéchal M, Cornell EH. Vocabulary acquisition through shared reading experiences. Reading Research Quarterly. 1993; 28:360-375.

Sénéchal M, LeFevre J. Parental involvement in the development of children's reading skill: A fiveyear longitudinal study. Child Development. 2002; 73:445-460. [PubMed: 11949902]

Sénéchal M, LeFevre J, Hudson E, Lawson EP. Knowledge of storybooks as a predictor of young children's vocabulary. Journal of Educational Psychology. 1996; 88:520-536.

Sénéchal M, LeFevre J, Thomas EM, Daley KE. Differential effects of home literacy experiences on the development of oral and written language. Reading Research Quarterly. 1998; 13:96-116.

Serpell R, Sonnenschein S, Baker L, Ganapathy H. Intimate culture of families in the early socialization of literacy. Journal of Family Psychology. 2002; 16:391-405. [PubMed: 12561284]

Shatil E, Share D. Cognitive antecedents of early reading ability: A test of the modularity hypothesis. Journal of Experimental Child Psychology. 2003; 86:1-31. [PubMed: 12943615]

Sonnenschein S, Munstermann K. The influence of home-based reading interactions on 5-year-olds' reading motivations and early literacy development. Early Childhood Research Quarterly. 2002; 17:318-337.

Stipek D, Feiler R, Daniels D, Milburn S. Effects of different instructional approaches on young children's achievement and motivation. Child Development. 1995; 66:209-223. 
Stipek D, Milburn S, Clements D, Daniels DH. Parents' beliefs about appropriate education for young children. Journal of Applied Developmental Psychology. 1992; 13:293-310.

Storch, SA.; Whitehurst, GJ. The role of family and home in the literacy development of children from low-income backgrounds. In: Britto, PR.; Brooks-Gunn, J., editors. The role of family literacy environments in promoting young children's emerging literacy skills. New directions for child and adolescent development. San Francisco: Jossey-Bass; 2001. p. 53-71.

Storch SA, Whitehurst GJ. Oral language and code-related precursors to reading: Evidence from a longitudinal structural model. Developmental Psychology. 2002; 38:934-947. [PubMed: 12428705]

Torgesen, JK. Recent discoveries on remedial interventions for children with dyslexia. In: Snowling, M.; Hulme, C., editors. The science of reading: A handbook. Malden, MA: Blackwell; 2005. p. 521-537.

Torgesen JK, Alexander AW, Wagner RK, Rashotte CA, Voeller KK, Conway T. Intensive remedial instruction for children with severe reading disabilities: Immediate and long-term outcomes from two instructional approaches. Journal of Learning Disabilities. 2001; 34:33-58. [PubMed: 15497271]

Vigil, D. Joint attention in cultural context; Paper presented to the American Speech-LanguageHearing Association; San Francisco, CA. 1999 Nov.

Wagner RK, Torgesen JK, Rashotte CA. Development of reading-related phonological processing abilities: New evidence of bidirectional causality from a latent variable longitudinal study. Developmental Psychology. 1994; 30:73-87.

Weizman ZO, Snow CE. Lexical input as related to children's vocabulary acquisition: Effects of sophisticated exposure and support for meaning. Developmental Psychology. 2001; 37:265-279. [PubMed: 11269394]

Whitehurst GJ, Arnold DH, Epstein JN, Angell AL, Smith M, Fischel JE. A picture book reading intervention in daycare and home for children from low-income families. Developmental Psychology. 1994; 30:679-689.

Whitehurst GJ, Lonigan CJ. Child development and emergent literacy. Child Development. 1998; 68:848-872. [PubMed: 9680688]

Yarosz DJ, Barnett WS. Who reads to children?: Identifying predictors of family reading activities. Reading Psychology. 2001; 22:67-81.

Zayas LH, Solari F. Early childhood socialization practices in Hispanic families: Context, culture, and practical implications. Professional Psychology: Research and Practice. 1994; 25:200-206.

Zea MC, Quezada T, Belgrave FZ. Latino cultural values: Their role in adjustment to disability. Journal of Social Behavior and Personality. 1994; 9:185-200. 


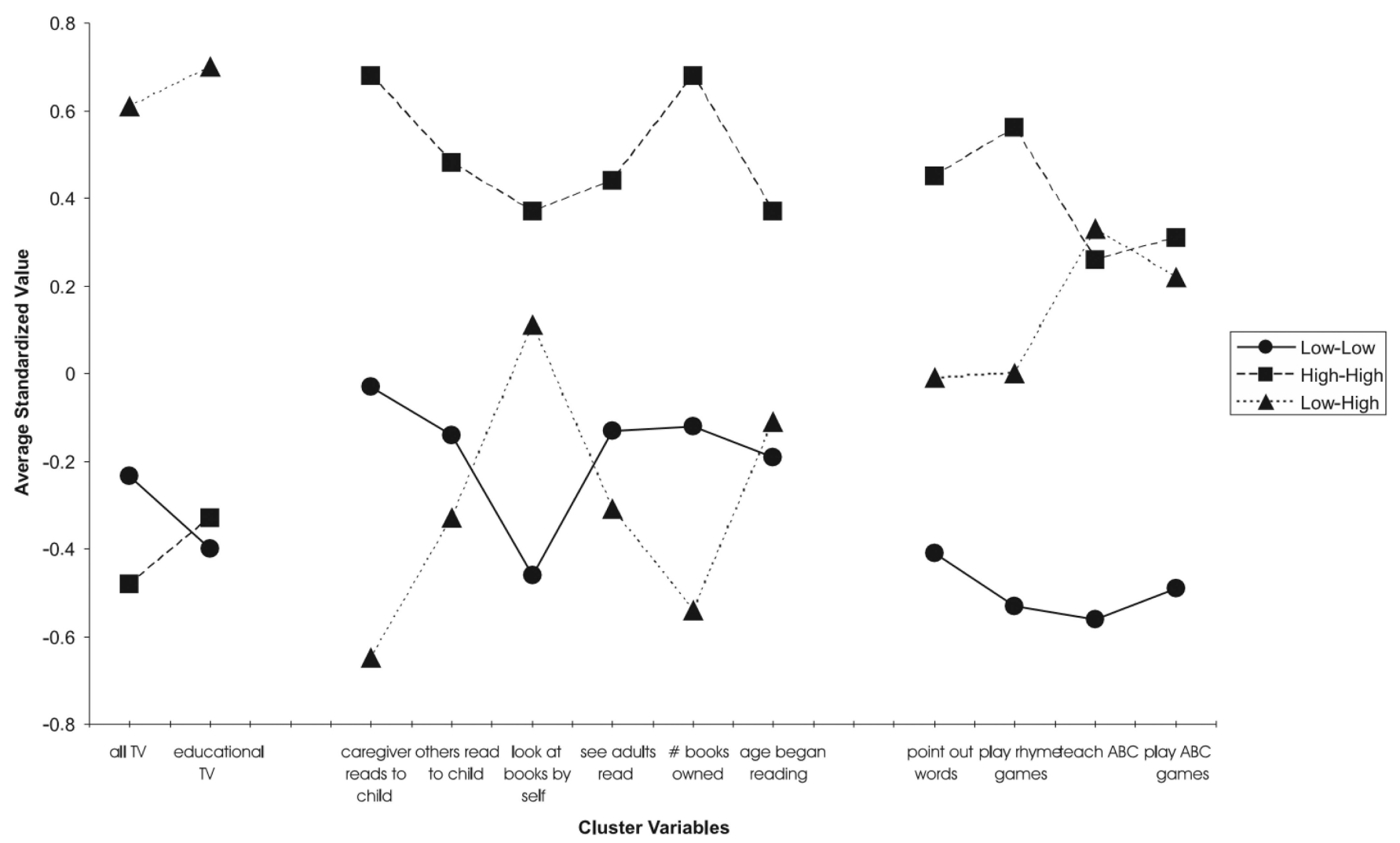

Figure 1.

Performance on home literacy behaviors for each of three clusters. Note. $n=357$ for Cluster 1, "low-low"; $n=344$ for Cluster 2, "high-high"; $n=343$ for Cluster 3, "low-high." All values are standardized within the full sample. All TV = hours per day of television viewing; educational TV = hours per day of educational television viewing; caregiver reads to child = number of times per week child read to by primary caregiver; others read to child $=$ number of times per week child read to by others; look at books by self $=$ number of times per week child looks at books by self; see adults read = frequency with which child observes caregivers reading; \# books owned = number of children's books owned by household; age began reading $=$ age in months at which caregiver began reading to child, reversed so that higher value represents a younger age; point out words $=$ frequency with which caregiver points out words in the environment to child; play rhyme games = frequency with which caregiver plays rhyming games with child; teach $\mathrm{ABC}=$ frequency with which caregiver teaches child the alphabet; play $\mathrm{ABC}$ games $=$ frequency with which child plays alphabet games. 
Table 1

Descriptive Characteristics of Primary Caregiver Survey Respondents

\begin{tabular}{lrrc}
\hline Characteristic & $\boldsymbol{M}$ & $\boldsymbol{S D}$ & Range \\
\hline Family income (dollars) & $54,666.19$ & $53,022.91$ & $7,500-275,000$ \\
Caregiver education (years) & 14.65 & 2.52 & $2-26$ \\
Caregiver reading ability & 3.41 & 0.61 & $1-4$ \\
$\%$ with multiple children/ Average no. of additional children & $77.1 / 1.23$ & 1.07 & $0-8$ \\
$\%$ living with spouse of partner & 78.9 & - & - \\
$\%$ working outside the home & 79.2 & - & - \\
Stress level & 1.00 & 0.97 & $0-3$ \\
\hline
\end{tabular}

Note. $N=1044$. Income level scored in 10 intervals ranging from less than or equal to $\$ 15,000 /$ year to greater than $\$ 200,000 /$ year; overall sample mean and standard deviation computed by assigning each case the median value for its interval. 
Table 2

Descriptive Characteristics of Home Literacy Environment

\begin{tabular}{lrrr}
\hline Characteristic & $\boldsymbol{M}$ & $\boldsymbol{S D}$ & Range \\
\hline Child watches television (hours per day) & 2.46 & 1.34 & $0-10$ \\
Child watches educational television (hours per day) & 1.58 & 1.05 & $0-6$ \\
Primary caregiver reads to child (times per week) & 4.69 & 2.11 & $0-8$ \\
Others read to child (times per week) & 2.62 & 2.03 & $0-8$ \\
Child looks at books by self (days per week) & 4.84 & 1.93 & $0-8$ \\
Child sees adults engage in reading for pleasure $b$ & 4.73 & 1.58 & $0-6$ \\
Number of children's books own & ( & & \\
Age began reading to child (months) & 67.69 & 58.44 & $0-300$ \\
Caregiver points out words to child $b$ & 6.03 & 6.00 & $0-36$ \\
Caregiver plays rhyming games with child $b$ & 4.86 & 1.46 & $0-6$ \\
Caregiver teaches alphabet to child $b$ & 3.11 & 1.87 & $0-6$ \\
Child plays with alphabet toys/ games $b$ & 4.26 & 1.59 & $0-6$ \\
Child visits library (times per month) & 3.56 & 1.65 & $0-6$ \\
\hline
\end{tabular}

Note. $N=1,044$.

${ }^{a}$ Mean and standard deviation were calculated by assigning each respondent the median value for their response interval.

${ }^{b}$ Responses for these five questions were selected from 0 (never) to 7 (daily). 


\section{로을}

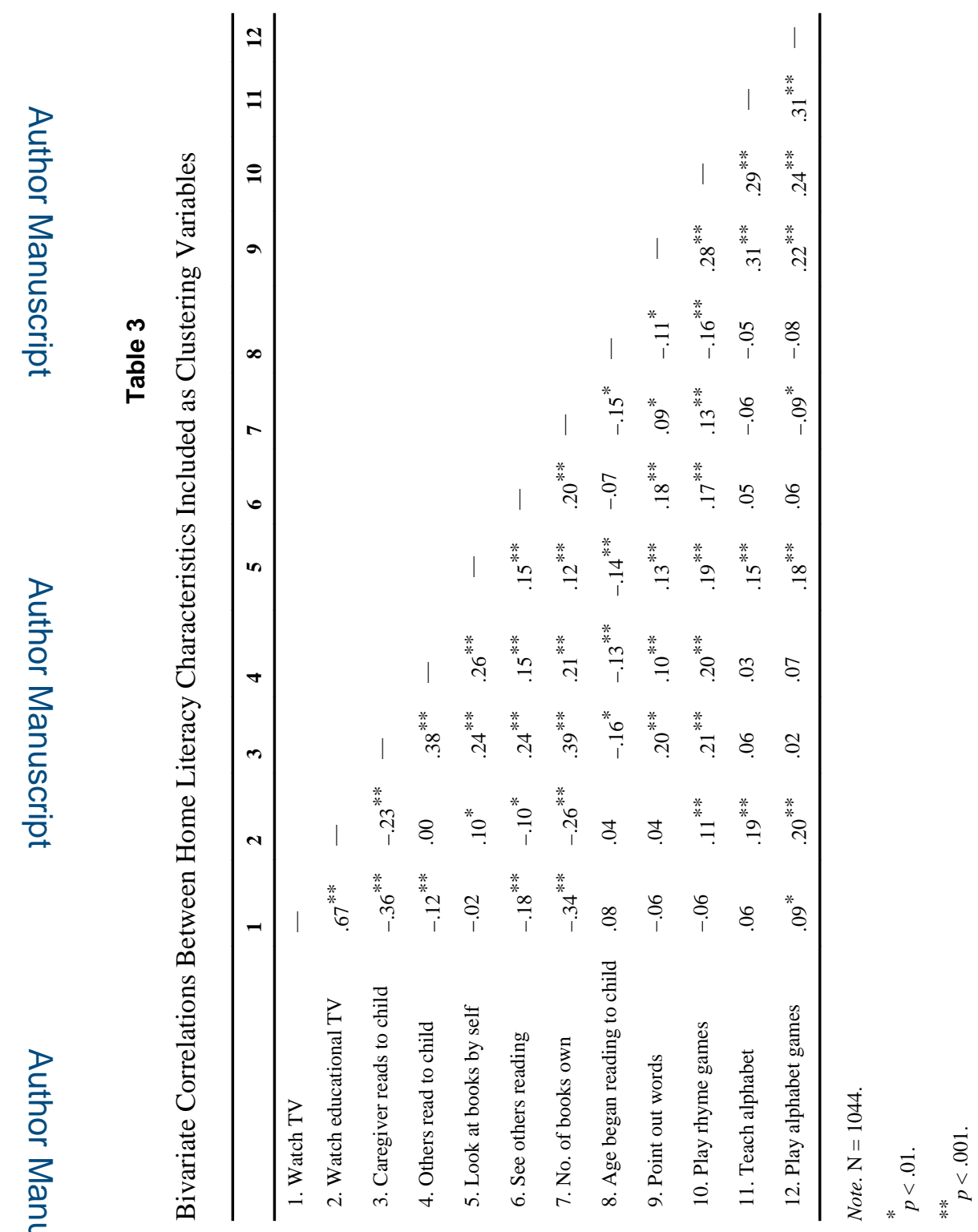

Sci Stud Read. Author manuscript; available in PMC 2015 March 16. 
Table 4

Means (Standard Deviations) for Variables Representing Three-Cluster Solution in Full Sample

\begin{tabular}{lccc}
\hline & $\begin{array}{c}\text { Cluster 1 } \\
\text { "Low-Low"a }\end{array}$ & $\begin{array}{c}\text { Cluster 2 } \\
\text { "High-High" } \boldsymbol{b}\end{array}$ & $\begin{array}{c}\text { Cluster 3 } \\
\text { "Low-High"c }\end{array}$ \\
\hline Watch TV (per day) & $2.15^{a}(1.17)$ & $1.76^{b}(0.94)$ & $3.48^{c}(1.23)$ \\
Watch educational TV (per day) & $1.14^{a}(0.81)$ & $1.22^{a}(0.72)$ & $2.38^{b}(1.10)$ \\
Books own & $60.25^{a}(43.44)$ & $106.99^{b}(69.71)$ & $36.01^{c}(30.94)$ \\
Caregiver read (per week) & $4.64^{a}(1.95)$ & $6.11^{b}(1.52)$ & $3.32^{c}(1.83)$ \\
Others read (per week) & $2.33^{a}(1.82)$ & $3.59^{b}(2.17)$ & $1.95^{c}(1.70)$ \\
Books-self (per week) & $3.96^{a}(1.97)$ & $5.55^{b}(1.82)$ & $5.05^{c}(1.60)$ \\
See adults reading & $4.52^{a}(1.72)$ & $5.43^{b}(0.90)$ & $4.23^{c}(1.72)$ \\
Age began reading (months) & $7.37^{a}(7.69)$ & $3.79^{b}(4.12)$ & $6.89^{a}(4.86)$ \\
Point-words & $4.25^{a}(1.81)$ & $5.52^{b}(0.74)$ & $4.85^{c}(1.32)$ \\
Rhyme games & $2.12^{a}(1.72)$ & $4.15^{b}(1.43)$ & $3.11^{c}(1.86)$ \\
Teach ABC & $3.36^{a}(1.67)$ & $4.67^{b}(1.49)$ & $4.77^{b}(1.12)$ \\
ABC games & $2.75^{a}(1.63)$ & $4.06^{b}(1.31)$ & $3.91^{b}(1.64)$ \\
\hline
\end{tabular}

Note. $N=1,044$. Means identified by a different subscript differ at $p<.05$ after Bonferroni correction.

$a_{N=357 .}$

${ }^{b} N=344$.

$c_{N}=343$. 
Table 5

Descriptive Characteristics on Additional Related Variables for Three Clusters Within Full Sample

\begin{tabular}{|c|c|c|c|}
\hline & $\begin{array}{l}\text { Cluster } 1 \\
\text { "Low-Low" } a\end{array}$ & $\begin{array}{l}\text { Cluster } 2 \\
\text { "High-High" } b\end{array}$ & $\begin{array}{l}\text { Cluster } 3 \\
\text { "Low-High" } c\end{array}$ \\
\hline Family income (dollars) & $64,709(56,587)^{a}$ & $73,951(53,985)^{b}$ & $24,873(30,797)^{c}$ \\
\hline Caregiver education (years) & $15.07(2.38)^{a}$ & $15.78(2.34)^{b}$ & $13.07(2.01)^{c}$ \\
\hline Caregiver reading ability & $3.35(0.61)^{a}$ & $3.57(0.53)^{b}$ & $3.32(0.65)^{a}$ \\
\hline$\%$ with multiple children & 78.4 & 74.5 & 78.4 \\
\hline Number of children & $1.24(1.14)^{a, b}$ & $1.06(0.91)^{a}$ & $1.38(1.09)^{b}$ \\
\hline$\%$ living with spouse of partner & $81.0^{a}$ & $90.0^{b}$ & $65.0^{c}$ \\
\hline$\%$ working outside the home & $82.1^{a}$ & $78.2^{a}$ & $77.3^{a}$ \\
\hline Stress level & $1.11(0.97)^{a}$ & $0.90(0.94)^{b}$ & $0.99(0.98)^{a, b}$ \\
\hline Child enjoyment or shared reading & $3.43(0.76)^{a}$ & $3.75(0.55)^{b}$ & $3.26(0.90)^{c}$ \\
\hline Library visits & $0.95(1.19)^{a}$ & $1.28(1.33)^{b}$ & $0.82(1.25)^{a}$ \\
\hline
\end{tabular}

Note. $N=1,044$. Means identified by a different subscript differed at $p<.05$ after Bonferroni correction.

$a_{N=357 .}$

$b_{N}=344$.

${ }^{c} N=343$. 
Table 6

Classification Rates From Discriminant Analysis of Exogenous Variables

\begin{tabular}{lccc}
\hline & $\begin{array}{c}\text { Cluster 1 } \\
\text { "Low-Low"a }\end{array}$ & $\begin{array}{c}\text { Cluster 2 } \\
\text { "High-High"b }\end{array}$ & $\begin{array}{c}\text { Cluster 3 } \\
\text { "Low-High"c }\end{array}$ \\
\hline Correctly classified & $38.4 \%$ & $57.3 \%$ & $78.0 \%$ \\
Misclassified & Cluster 2: 35.0\% & Cluster 1: 26.7\% & Cluster 1: 11.1\% \\
& Cluster 3: 26.6\% & Cluster 3: 16.0\% & Cluster 2: 10.9\% \\
\hline
\end{tabular}

Note. $N=1,044$. 